\title{
Option Compensation and Industry Competition
}

\author{
Neal M. Stoughton \\ Kit Pong Wong \\ University of Calgary \\ The University of Hong Kong
}

Latest Draft: August 2007

\begin{abstract}
Compensation policy has become one of the most important ingredients of corporate governance. In this paper we take a new look at the issue, by contrasting the use of options with that of pure stock. We do this by integrating the repricing or resetting aspect of options with that of industrial structure. We show that industry competition may play an important role in dictating which form of compensation is optimal. When aggressive competition for key professional staff is an issue, the flexibility of options may actually become a disadvantage and therefore pure stock compensation may survive as an equilibrium. Thus compensation trends can be reconciled with trends in the nature of the competitive environment.
\end{abstract}

\section{Introduction}

One of the most significant trends of the 1990s was the extent to which equity-based pay accelerated at an incredibly rapid rate. As documented in Hall (2002) the amount of equity-based pay (as a fraction of total top executive pay) at the beginning of 1990 was less than 10\%. By 1992 this fraction was about $30 \%$ and by the end of the decade had reached over $60 \%$. The vast majority of this trend was accounted for by increases in the use of executive stock options.

But executives were not alone in benefitting from options. This privilege was also extended to many professional workers especially in high technology firms. Nevertheless more employees participate

We appreciate the very helpful comments of Chongwoo Choe, Dan Givoly, Sudipto Dasgupta, Jack Hughes, two anonymous referees and seminar participants at the European Finance Association, Calgary, ISCTE (Lisbon), Lausanne, UCLA and Washington University. Stoughton acknowledges support from the Social Sciences and Humanities Research Council of Canada. Financial support to Wong has been provided by the University Grants Committee of the Hong Kong SAR China (Project No. AoE/H-05/99) and is gratefully acknowledged. 
in share ownership plans as compared to stock options plans. ${ }^{1}$ Data from the National Center for Employee Ownership (NCEO) and the US General Social Survey puts the estimate of employees holding stock through company plans at abut 20 million in 2006. About 10.6 million hold stock options in their own firm. Trends such as these have been praised by academics and practitioners alike in terms of resolving agency problems and aligning the interests of shareholders and employees. Figure 1 shows the distribution of percent ownership by plan type for various stock-based incentive plans. ${ }^{2}$ For instance, note that 65 percent of option plans feature a concentration of ownership between 11-30\% of the amount of stock outstanding, as compared with only 10 percent in the case of $401(\mathrm{k})$ plans. On the other hand, 85 percent of the latter plans have ownership concentrations at the lowest level compared to 32 percent in the case of stock options. Since 401(k) plans predominantly hold stock rather than options, this indicates that percentage ownership concentrations are typically much lower for stock than for option plans within firms. This is a feature that we will exploit in our model.

Nevertheless, there is strong evidence that the trend towards option compensation has reversed in recent years. Based on a survey of 350 of the largest public companies, Mercer Consulting (Mercer, 2006) reports significant changes in the long term incentive mix beginning in about 2002. For instance, 295 companies awarded stock options to their CEOs in 2002 compared with 278 in 2003 and only 273 in 2004. Concomitantly 104 CEOs were given stock grants in 2002, 138 in 2003 and 166 in 2004. Figure 2 illustrates the dramatic changes in the typical CEO compensation packages. In 2002, 72\% of CEOs received options, which declined to $62 \%$ in 2003 and had decreased to only $52 \%$ in 2005 . Such changes in compensation have also been broad-based as some firms have replaced stock option plans for employees with pure stock grants.

The purpose of this paper is to provide a theory of employee compensation that is capable of explaining recent trends away from exclusive use of options. Our theory is based on looking at the use of employee compensation for strategic purposes in industry product market competition for scarce labor resources. In our model, firms choose their compensation policies in a multi-period strategic game in order to position themselves more strongly against their product market rivals. When firms already

\footnotetext{
${ }^{1}$ There are a number of empirical studies showing that broad-based employee ownership improves shareholder value (Blasi, Kruse and Bernstein, 2003).

${ }^{2}$ Data are from the NCEO and based on surveys as well as databases.
} 


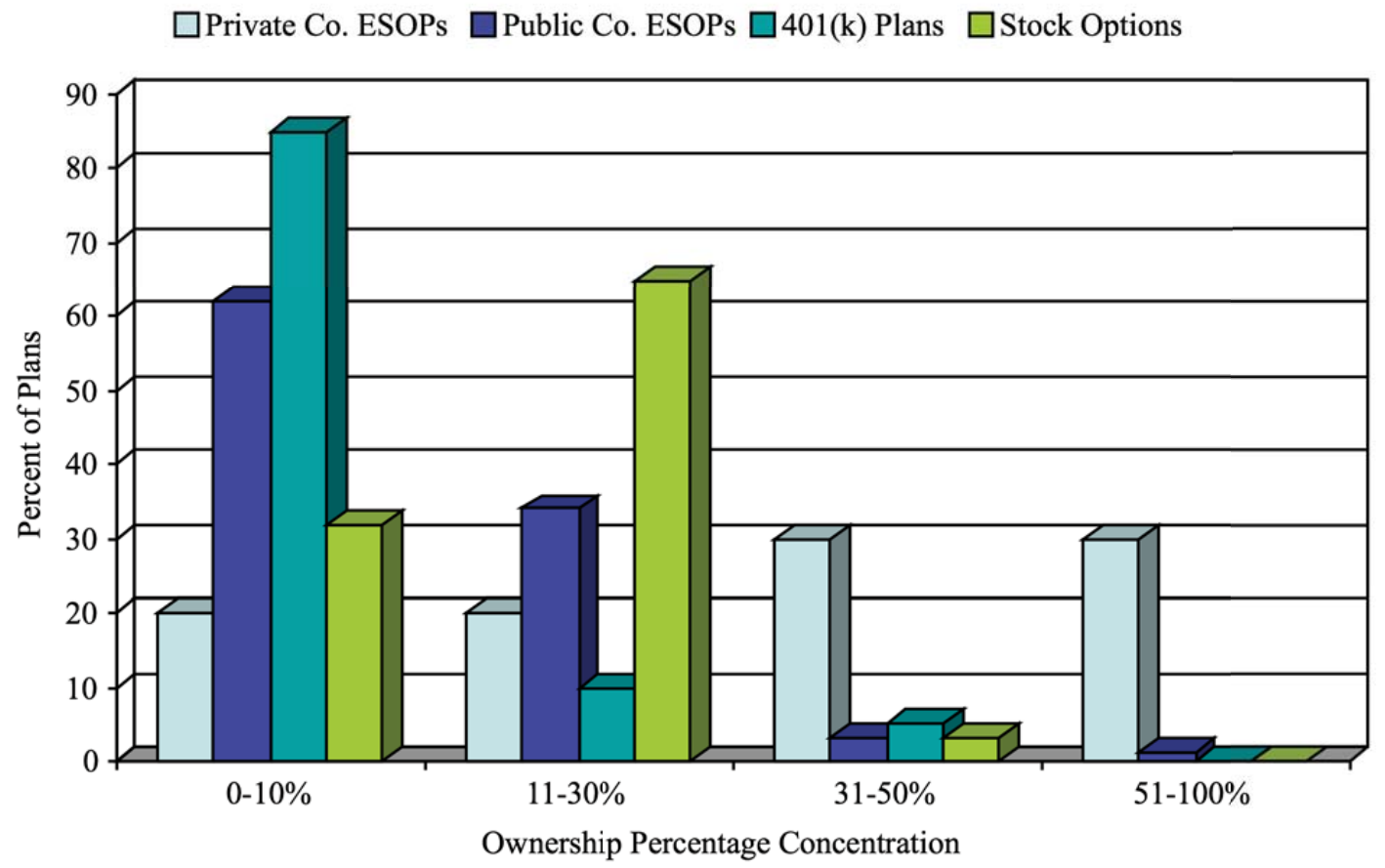

Figure 1: Percentage Ownership Concentration by Plan Type. The differences in the employee concentration levels are illustrated for four quantiles: plans where employees own up to $10 \%$ of the firm; $11-30 \%$ employee ownerships; 31-50\% ownership and 51-100\% ownership. The bars show the percent of plan type that features concentrations in each quantile. Data from the NCEO.

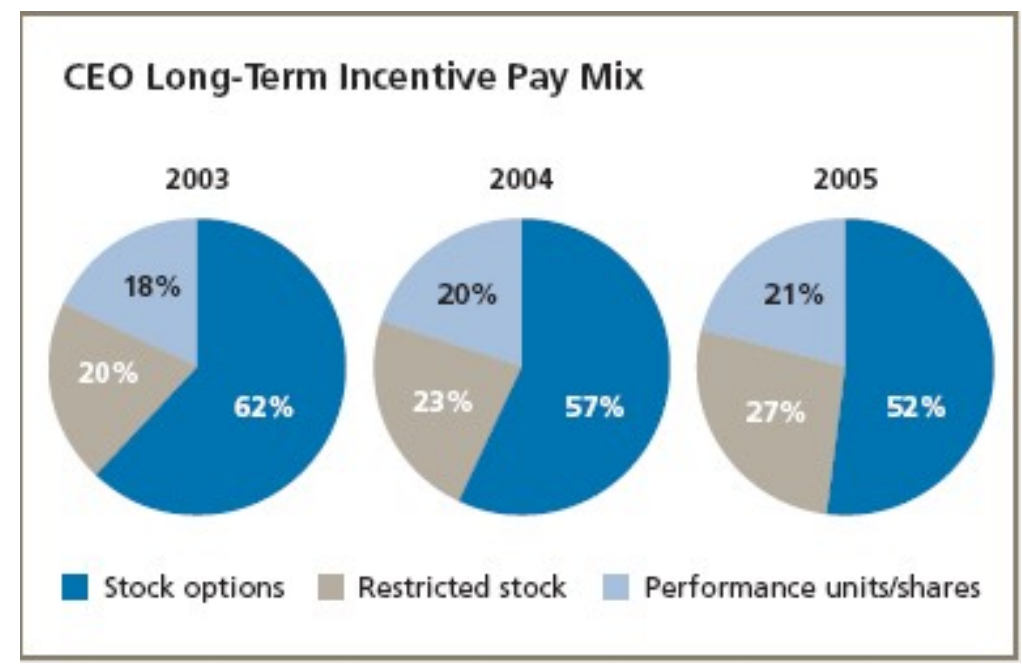

Figure 2: Chages in the Mix of Incentive Compensation. Data from the WSJ Mercer Consulting Survey. 
have dominant market power or face a very elastic supply for key personnel, we show that the flexibility of options dominates straight stock compensation. However this can change when competitive forces strengthen and/or key personnel become scarce.

Our key insight is as follows. Since option compensation involves an exercise price paid by employees, the number granted to achieve incentives has to be greater than the number of shares granted in the form of stock compensation in order to achieve the same incentives. Importantly this has the implication that when a firm faces the opportunity to bid away its rivals employees a stock-based compensation scheme leaves more residual surplus with which to bargain for these workers. If instead the firm utilized options, the greater degree of dilution due to sharing its potential surplus with existing employees puts the firm in a weaker bargaining position. Therefore we find that the nature of compensation plays an important role in determining the offensive strength of bargaining for key personnel. On the other hand, we find that compensation does not play a defensive role against a raid by the rival firm. By analyzing the economic conditions of an industry we specify exactly when firms would choose stock compensation instead of options in an industry equilibrium. We find that when the potential for market leadership is greater and when there is a lower probability of adverse disadvantage against a rival, the optimal compensation policy uses stock. When these conditions are lessened we find a heterogeneous equilibrium in which one firm uses stock while its rival uses options. Finally when these conditions are violated, both firms use option compensation. Therefore recent changes in compensation can be accounted for by life-cycle changes in industry structure.

The extent to which firms face competitive pressures in a tight market for professional talent is illustrated by the recent disclosures concerning option backdating, which came to light in 2006 ((Lie, 2005)). Since backdating obviously implies a reduction in exercise price, it makes options look more like a retroactive stock grant $]^{3}$ of course another explanation for the trend away from options could be the FASB changes in expensing rules which came into force in 2005.

Our paper follows in the tradition of literature on product market competition and financial strategy, such as Brander and Lewis (1986) and Maksimovic (1988). While many papers have considered the question of options v. stock in recent years, ours is the first to consider strategic product market

\footnotetext{
${ }^{3}$ The first CEO prosecuted, Gregory Reyes of Brocade Communications, was convicted in 2007 of accounting fraud. However he only backdated the options of others; not his own.
} 
implications between rival firms. Examples of important papers that consider stock v. options in a single firm include Hall and Murphy (2000) who propose a method of assessing the optimality of exercise prices and show via numerical methods that options should be issued near the money. On the other hand Dittmann and Maug (2007) consider a standard principal-agent model with constant relative risk aversion and lognormal stock prices and find that stock would dominate options in terms of compensation costs. They conclude that most executive pay was suboptimally determined at the time their data was sampled. Feltham and $\mathrm{Wu}(2001)$ consider an explicit agency model and show that results on compensation form are sensitive to the functional relation between effort and risk. When effort does not affect the risk of cash flow outcomes, they find that stock dominates at-the-money options.

There are also quite a few papers that extend the static analyses of compensation to a dynamic (continuous time) environment, again for a single firm in isolation. Risk aversion and inherent illiquidity are highlighted in the paper by Kahl, Liu and Longstaff (2003) who derive the implications for an undiversified portfolio on personal valuation and portfolio composition for restricted stock. An analogous paper in the case of stock options is that of Ingersoll (2006), who shows that the Black-Scholes model can be applied for private valuations, albeit with non-standard parameter inputs. Cadenillas, Cvitanić and Zapatero (2004) consider the optimal choice of exercise price in a moral hazard cum delegation model in which there is a tradeoff between effort and volatility choice. In each of these papers the original contract represents a commitment by the firm throughout the relevant time horizon, and is never revised unlike our paper.

The issue of option repricing has been extensively analyzed both from theoretical as well as empirical perspectives in recent years. Acharya, John and Sundaram (2000) consider the conditions under which resetting instead of precommitment to maintain exercise prices are optimal. Their tradeoff, which is the rent appropriated by the agent in down states with the efficiency induced by reincentivization in those states is basically the same as in our model of accounting choice. In a related paper Saly (1994) develops both a theoretical model as well as an empirical test of option repricing following an exogenous negative shock (i.e., not under the control of an agent). Her predictions are borne out when confronted with the data following the 1987 stock market crash. Other relevant papers on the subject 
of option repricing include Carter and Lynch (2001), Grein, Hand and Klassen (2005), Chidambaran and Prabhala (2003), Yang and Carleton (2002) and Jin and Meulbroek (2002).

In section 2 we propose a simple agency model of a dynamic model of uncertain production. We first analyze a specific numerical example to provide a preview of our later general results. In section 3 we conduct the analysis of a single firm and show under what conditions options strictly dominates stock. In section 4 we investigate an industry equilibrium situation with labor market competition as well as product market competition. Implications and extensions to our analysis are explored in section 5. Section 6 is the concluding section.

\section{The Basic Model and a Preview}

In this section we develop the basic version of our model and utilize a numerical example to preview our main result. The firm is in a multiperiod environment in which its professional staff must be incentivized in each period in order to create the highest possible market value. We look at the respective roles of the use of stock and option compensation in this respect. The model is based on that of Acharya et al. (2000). As in their paper, we assume that both the firm and its workers are risk-neutral.

\subsection{Details}

Consider a firm which lasts for two periods with three dates, $t=0,1$, and 2 . At $t=0$, owners of the firm hire a manager and professional staff who all have to exert an unobservable effort at a personal cost, $v$, in order to innovate a new product, technology or a production process. As we are not considering conflicts between managers and the staff, we model them together as an aggregate agent. If the effort is exerted initially then with probability $p$ there is a favorable outcome ("no shock") and with probability $1-p$ there is an unfavorable outcome ("shock"). On the other hand, if effort is not exerted initially the shock occurs with certainty. Therefore initial effort is required to give the firm an opportunity to experience a better outcome. Examples of the types of shocks that can occur are unforseen circumstances such as the failure of clinical trials in the case of biotechnology, shifts in market demand for products, or changes in governmental policy. If the adverse shock occurs the highest level of profits or market value will be impossible to achieve. 
At the interim date, $t=1$, it is known whether a shock has occurred or not ${ }^{4}$ In either case a further unobservable effort is required in order to obtain higher profits. If the shock has not occurred, the total cost of product innovation is $c_{1}$ only if a further effort of $\mu_{1}$ is committed at $t=1$. In this case the final profit of the firm at time $t=2$ is denoted by $\pi_{m}\left(c_{1}\right)$. If no shock occurs and further effort is not expended the total cost of product innovation is $c_{2}>c_{1}$ and the final profit is $\pi_{m}\left(c_{2}\right)$. The profit functions are decreasing in costs and concave.

When the shock occurs, either because effort was initially expended and the outcome was unfavorable with probability $1-p$ or no initial effort was expended then a further effort expenditure at private cost $\mu_{2}$ will lead to an outcome in which product innovation cost is $c_{2}$ and profit is $\pi_{m}\left(c_{2}\right)$. If the $t=1$ effort is not expended, then product innovation cost is prohibitive and we assume the product is not developed and final profit, $\pi_{m}=0$.

In order to clarify the meaning of these time periods and states we make two assumptions. First, we assume that the cost of effort in the first period is sufficiently large relative to the cost of effort in the second period when a shock is observed. Second the relative net benefit (profits minus effort cost) is greater after no shock as compared to the shock state. These are stated as follows:

$$
\begin{gathered}
v / p>\mu_{2} \\
\frac{\mu_{1}}{\mu_{2}} \leq \frac{\pi_{m}\left(c_{1}\right)-\pi_{m}\left(c_{2}\right)}{\pi_{m}\left(c_{2}\right)} .
\end{gathered}
$$

In summary, the highest final profit is obtained if and only if effort is expended in both periods and the shock does not occur. The intermediate profit is obtained either if the shock does not occur but second period effort is neglected or if the shock occurs but second period effort is undertaken. The final profit is zero if no effort is expended in both periods.

Figure 3 illustrates the evolution of information from the perspective of the market value of the firm and the final distribution of terminal cash flows. The specific numerical values refer to the numerical example analyzed below.

\footnotetext{
${ }^{4}$ In an earlier draft of the paper (available on request), we analyzed a situation in which the shock was only privately observed by the firm, although the firm could commit to a reporting policy on what to reveal. The basic results on optimal compensation were preserved in this extension.
} 


$$
t=1 \quad t=2
$$

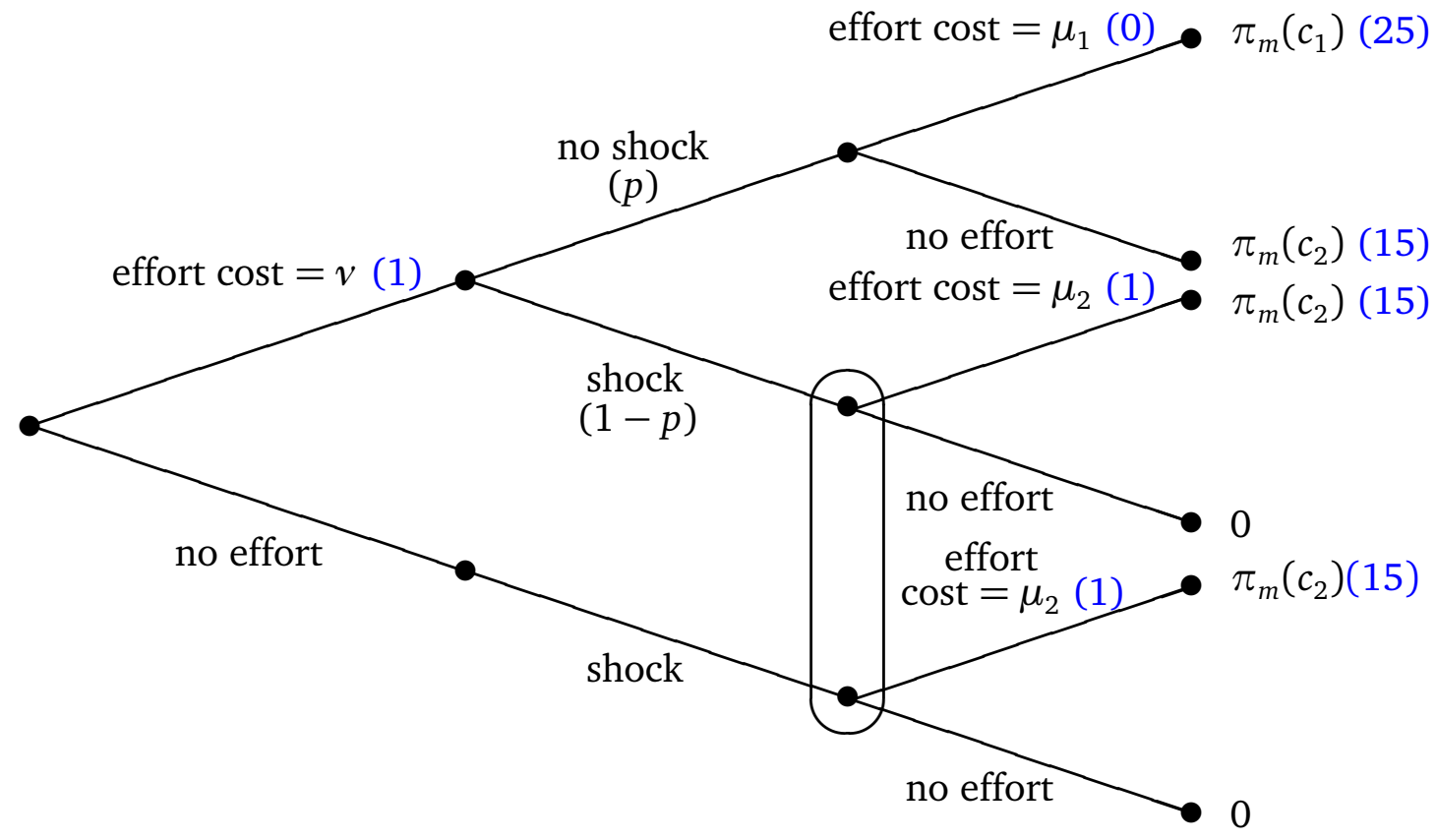

Figure 3: Evolution of information and distribution of terminal cash flows. Numbers in parenthesis refer to the numerical example of this section.

\subsection{Compensation Contracts}

In general with risk neutral parties, it is well-known that the first best outcome can be achieved by "selling" the firm to the agents. However this is only possible if they have vast wealth, which we believe to be unrealistic. Therefore the motivation will have to be achieved through appropriate compensation contracting.

We now consider two alternative compensation systems for the professional staff. Although clearly the actual set of compensation contracts in practice can be very complex and based on a wide variety of subjective and objective bonus and promotion-based criteria, here our purpose is to contrast the use of straight stock compensation and option compensation. An example of a more complicated contract would be the use of state-contingent stock compensation, e.g., stock grants based on future performance indices. In the context of this model, this form of compensation is similar to the use of options although we discuss the differences in section 5 . In the single firm model vesting will not matter because all employees remain with the firm, although for convenience we assume vesting occurs at the final date for both stock and option contracts. The major difference between the two forms of compensation deals 
with the possibility of resetting the exercise price of options at the interim date for reincentivization purposes.

\subsection{Numerical Example}

In order to preview the more general results of our model we utilize the numbers in parenthesis in figure 3 for a numerical illustration. We maintain the flexibility to consider the range of values for $p$ such that $0<p<3 / 5$. As is seen, the respective profit levels are $\$ 25$ without the shock and $\$ 15$ with the shock and subsequent effort. For the purpose of this example, further effort in the absence of the shock is costless $\left(\mu_{1}=0\right)$.

\subsubsection{Stock Compensation}

First consider the use of pure stock compensation with the number of shares given to employees equal to $s_{0}=(1-p) / 10 p$. To see that this is the minimum number of shares to induce effort, note that the net payoff for employees in the subtree at $t=1$ after the shock is

$$
s_{0} 15-1=\frac{5(3 / 5-p)}{2 p}>0,
$$

since $p<3 / 5$. The expected payoff to the employees for exerting initial effort at $t=0$ is

$$
p s_{0} 25+(1-p)\left(s_{0} 15-1\right)-1=\left(\frac{1-p}{10 p}\right) 15-1
$$

which is exactly equal to the payoff if the workers do not exert the initial effort. Now considering the payoff to shareholders owning the remaining $\left(1-s_{0}\right)$ shares, we find that

$$
V(\text { stock })=p\left(1-s_{0}\right) 25+(1-p)\left(1-s_{0}\right) 15=\frac{(11 p-1)(3+2 p)}{2 p} .
$$

\subsubsection{Option Compensation}

When options are employed, we assume that they are issued initially at-the-money, which means that the exercise price is set at $x_{0}=p 25+(1-p) 15=(15+10 p)$. In this case the optimal number of options 
granted to the employees can be shown to be equal to $\alpha_{0}=1 /(10 p(1-p))$. Notice that $\alpha_{0}=s_{0} /(1-p)^{2}$, which shows that the number of options granted when options are used is greater than the number of shares granted with pure stock compensation.

After the shock occurs it is necessary to reprice the options to induce effort. However this can be done in a manner to just induce effort without leaving any extra rent. Therefore in the subtree at $t=1$ after a shock the employees receive a gross payoff equal to one, the cost of extra effort, or a net payoff of zero. The expected ex ante payoff to the professional employees if they exert the initial effort at $t=0$ is therefore

$$
p \alpha_{0}\left(25-x_{0}\right)+(1-p) 0-1=0
$$

using the value of $\alpha_{0}$ from above. Therefore $\alpha_{0}$ from above is the minimum number of options to provide initial incentives. The firm's shareholders receive a net payoff of

$$
V(\text { options })=p\left(25-\alpha_{0}\left(25-x_{0}\right)\right)+(1-p)(15-1)=13+11 p .
$$

Note that the difference in payoff to the shareholders in the two compensation regimes is

$$
V(\text { options })-V(\text { stock })=13+11 p-\frac{(11 p-1)(15+10 p)}{10 p}=\frac{5(3 / 5-p)}{2 p}>0,
$$

since $p<3 / 5$. Hence, the firm always prefers option compensation to pure stock compensation. This is the main result proved in general in the next section that when firms are in isolation the generality of options compensation is better than stock compensation.

\subsubsection{Industrial Competition}

The above conclusion may not hold if there is industrial competition. Suppose that there is a rival firm that is susceptible to raiding of its key personnel by an incumbent firm. In the shock case, the incumbent firm faces the same scenario as described above: It has to induce its workers to exert the additional effort at $t=1$ in order to generate $\$ 15$. However, in the no-shock case, the incumbent firm encounters a choice of two strategies. The incumbent firm may attempt to recruit its rivals workers in 
order to obtain competitive advantage. We assume for example that this requires a payment of $\$ 7$ in total for the additional staff, but that additional gross profits equal to $\$ 35$ are then obtained at time $t=2$. If the incumbent is unable to accomplish this, then it would receive $\$ 25$ at $t=2$ as before.

Let us reconsider the previous stock and option compensation schemes, which remain incentive compatible to induce workers to expend effort in the first period. Consider the situation where the incumbent has used option compensation. In this case the net payoff to the firms shareholders after paying their own workers when it makes the takeover of the rival workforce is

$$
\left.V_{1} \text { (option, takeover }\right)=35-7-\alpha_{0}\left(35-x_{0}\right) \text {. }
$$

However if the potential takeover does not occur, the payoff is

$$
\left.V_{1} \text { (option, no takeover }\right)=25-\alpha_{0}\left(25-x_{0}\right) \text {. }
$$

The conditions under which no takeover is optimal becomes $3 p(1-p)<1$, which holds for all values of $p$. Therefore sharing the surplus profit with newly recruited and existing workers in the case of option compensation rules out this form of competitive advantage. As before, the incumbent firm using options obtains ex ante value equal to $V$ (options) $=13+11 p$.

Now, if the firm uses the pure stock compensation scheme, buying out the rival firm's workers is optimal if and only if the following condition holds:

$$
\left(1-s_{0}\right) 35-7>\left(1-s_{0}\right) 25
$$

which can be simplified to $p>1 / 4$. (If $p<1 / 4$, then the analysis is the same as in the single firm case and options are always dominant.) This is one of the keys to our analysis: the incumbent firm acts tougher in the subgame with respect to its rival after stock compensation is used, as compared to options compensation because there is more dilution of shareholder interests in the latter case.

If $1 / 4<p<3 / 5$, the incumbent firm will obtain a competitive advantage at time $t=1$. The ex 
ante profit becomes

$$
V(\text { stock })=p\left(1-s_{0}\right) 35-7+(1-p)\left(1-s_{0}\right) 15=\frac{(11 p-1)(3+4 p)}{2 p}-7 p
$$

With the consideration of industrial competition, the firm prefers pure stock compensation to option compensation if

$$
V(\text { stock })-V(\text { options })=\frac{(11 p-1)(3+4 p)}{2 p}-7 p-(13+11 p)=\frac{8 p^{2}+3 p-3}{2 p}>0
$$

which will hold whenever $p>(\sqrt{105}-3) / 160=0.453$. Therefore we have illustrated conditions under which stock compensation gives greater benefit to the firm than does option competition. In general the higher is $p$, the probability of not receiving the shock the more likely is pure stock compensation to survive as an optimal form of remuneration to the employees. Intuitively the absence of a downward shock gives it a greater potential to profit from competitive advantage against its rival.

\section{Single Firm Analysis}

We now develop the analysis of the full model and prove our results for the general model parameters. In the general model we consider the question of intertemporal contracting revisions.

\subsection{Stock Compensation}

Consider the use of pure stock compensation. In this case, at the initial date the firm grants the staff a fraction, $s_{0}$, of ending firm value. If necessary, at the interim date, the firm can grant the employees additional shares in order to induce effort in the second period. In no case is the firm allowed to reduce stock compensation granted at the initial date. We denote the (possibly revised) shares granted when there is no shock by $s_{1}$ and the shares granted with a shock by $s_{2}$.

Thus, in this case, the firm solves the following principal-agent problem: ${ }^{5}$

$$
\max _{s_{0}, s_{1}, s_{2}} p\left(1-s_{1}\right) \pi_{m}\left(c_{1}\right)+(1-p)\left(1-s_{2}\right) \pi_{m}\left(c_{2}\right)
$$

\footnotetext{
${ }^{5}$ We assume the parameter values are such that the firm wants to induce full effort in both periods.
} 
subject to

$$
\begin{gathered}
p s_{1}\left(\pi_{m}\left(c_{1}\right)-\mu_{1}\right)+(1-p)\left[s_{2} \pi_{m}\left(c_{2}\right)-\mu_{2}\right]-v \geq s_{2} \pi_{m}\left(c_{2}\right)-\mu_{2}, \\
s_{1}\left(\pi_{m}\left(c_{1}\right)-\pi_{m}\left(c_{2}\right)\right) \geq \mu_{1}, \\
s_{2} \pi_{m}\left(c_{2}\right) \geq \mu_{2}, \\
s_{1} \geq s_{0} \\
s_{2} \geq s_{0}
\end{gathered}
$$

where (4) is the incentive compatibility constraint for the provision of effort at $t=0,(5)$ and (6) are the staff's subgame perfect incentive compatibility constraints for effort at $t=1$ and equations (7) and (8) ensure that the stock compensation is not state contingent, i.e., the grant may not be reduced at $t=1$.

In the solution to (3) we can show that under our previous meaningful economic assumptions the incentive compatibility constraint for initial effort, (4) is always binding. We can regard the firm as using this constraint to establish the initial value of stock compensation $s_{0}$. Then the compensation may or may not need to be revised upward at $t=1$ in the shock state. Compensation will never need to be revised upward in the no shock state because initial incentives are always sufficient for interim date incentives. We state our formal results in the following proposition.

Proposition 1. In the solution to the stock compensation problem (3), the initial incentive compatibility constraint, (4), is binding under assumptions (1) and (2). There are two cases. Whenever

$$
v / p>\mu_{2} \frac{\pi_{m}\left(c_{1}\right)}{\pi_{m}\left(c_{2}\right)}-\mu_{1}
$$

the initial compensation level, $s_{0}=s_{1}=s_{2}$ is sufficient for interim incentives and both interim incentive compatibility constraints, (5) and (6) are not binding. Whenever

$$
v / p \leq \mu_{2} \frac{\pi_{m}\left(c_{1}\right)}{\pi_{m}\left(c_{2}\right)}-\mu_{1}
$$


the initial compensation level, $s_{0}=s_{1}$ and $s_{2}>s_{0}$, is adjusted upward only in the state after the adverse shock. In this case the interim incentive compatibility constraint (5) is not binding while constraint (6) is binding.

Proof. See the appendix.

This proposition shows that (9) is the key condition governing the situation under which the stock compensation established initially for the first period effort is sufficient to sustain incentives for the second period after a shock. This condition is likely to hold whenever the cost of first period effort is large compared to the second period effort cost, or if the probability of not having a shock is small or if the difference in profit in the two states is not very large. In this case the firm needs to make an ex ante commitment in the form of a sizeable stock grant at the initial date in order to commit to sufficient compensation at the interim date. However this commitment overcompensates the workers in both states and they earn rents at that time. When condition (10) holds, reincentivizing the workers is necessitated when the shock occurs because setting initial incentives too high only gives workers excess rents in the no shock state. Therefore in this latter case the workers earn zero rents in the shock state but positive rents in the no shock state. These rents occur because stock compensation cannot be withdrawn or reduced at the interim date.

To solve for the optimal level of initial stock compensation when (9) holds, we can set (4) as an equality with $s_{1}=s_{2}=s_{0}$ and solve for $s_{0}$. We then obtain the following

Corollary 1. When (9) holds the solution for the optimal initial stock compensation is

$$
s_{0}^{*}=\frac{(v / p)-\left(\mu_{2}-\mu_{1}\right)}{\pi_{m}\left(c_{1}\right)-\pi_{m}\left(c_{2}\right)} .
$$

Similarly we can solve for the optimal initial compensation when the condition (10) holds.

COROLlary 2. When condition (10) holds, the solution for the optimal initial stock compensation is

$$
s_{0}^{*}=\frac{(v / p)+\mu_{1}}{\pi_{m}\left(c_{1}\right)}
$$

We can now solve for the optimal value of the shareholders equity in the stock compensation case 
as a function of the stock compensation level. Recall from proposition 1 that the initial incentive compatibility constraint, (4), is binding. Substituting this with equality into the objective function (3) gives the following result.

COROLLARY 3. The shareholder value in the optimal stock compensation is equal to

$$
V(\text { stock })=p \pi_{m}\left(c_{1}\right)+(1-p) \pi_{m}\left(c_{2}\right)-v-p \mu_{1}-(1-p) \mu_{2}-\left[s_{2} \pi_{m}\left(c_{2}\right)-\mu_{2}\right]
$$

Notice that equation (13) shows that the shareholders value is equal to the aggregate expected profit minus the expected costs of effort expenditure (first and second period) less the rent given to the workers in the shock state, which is equal to $s_{2} \pi_{m}\left(c_{2}\right)-\mu_{2}$. Notice importantly that the rent to workers in the no shock state does not enter into the shareholder value equation. This is because the firm wants to encourage the employees to undertake effort. Any surplus in the no shock state occurs only after effort is undertaken and therefore benefits the shareholders. Any surplus in the shock state is costly to them because it means that they might have failed to exert effort initially. At the optimal contract, the surplus in the no shock state is the minimal amount required to provide initial incentives. Corollary 3 establishes further that equation (9) of proposition 1 is the crucial determinant of whether the surplus is positive or not, and therefore costly to shareholders. This condition is equivalent to having a nonbinding incentive compatibility constraint in the second period when the shock occurs. Otherwise when this condition does not hold initial stock compensation is adjusted upward, $s_{2}>s_{0}$ such that $s_{2} \pi_{m}\left(c_{2}\right)=\mu_{2}$. In this case there is surplus given to the workers in the no shock state but this is not costly to the firm ex ante.

\subsection{Options Compensation}

Now we consider options-based compensation. Here the firm grants the staff $\alpha_{0}$ call options on firm value with an exercise price, $x_{0} 6$ The firm sets the exercise price, $x$, such that the call options are at the money at $t=0$, which is the practice followed by most firms. We assume in this model that accounting considerations such as whether options are expensed or not have no cash-flow consequences

\footnotetext{
${ }^{6}$ We do not consider the leverage-related effects due to the difference between the fact that options are typically written on stock, not overall firm value. Strategic use of debt policy might have consequences similar to that considered here (Brander and Lewis, 1986) and (Maksimovic, 1988)
} 
to shareholders or employees. Thus, we have $\pi_{m}\left(c_{2}\right)<x_{0}<\pi_{m}\left(c_{1}\right)$. It is clear that when the adverse shock occurs at $t=1$, the call options will be underwater. If resetting of the call options is not allowed, the staff will have no incentives to devise the restructuring process at $t=1$ since $\mu_{2}>0$. To give them proper incentives, the firm grants $\alpha_{2}$ new call options with an exercise price, $x_{2}$, to the staff. The firm now has to choose the options to be 'in the money' in order to provide the requisite incentives at $t=1$. Thus, we have $0<x_{2}<\pi_{m}\left(c_{2}\right) \cdot 7$ Again, we assume that there are no direct or deadweight costs of repricing options so that considerations such as variable accounting or regulatory expenses associated with canceling and regranting are neglected.

When effort is initially expended and the firm does not incur the adverse shock then the options will be in the money eventually only if the workers expend second period effort. Therefore it is not necessary to reset the exercise price in this case. Still depending on the original number of options granted, it might be necessary to increase them in order to reincentivize the workers.

The principal-agent problem faced by the firm using options is similar to that of (3) except that using the resetting feature, we know that the incentive compatibility constraint in the case with the shock is binding. At $t=0$, the firm solves the following principal-agent problem 8

$$
\max _{\alpha_{0}, \alpha_{1}, \alpha_{2}} p\left\{\pi_{m}\left(c_{1}\right)-\alpha_{1}\left[\pi_{m}\left(c_{1}\right)-x_{0}\right]\right\}+(1-p)\left\{\pi_{m}\left(c_{2}\right)-\alpha_{2}\left[\pi_{m}\left(c_{2}\right)-x_{2}\right]\right\}
$$

subject to

$$
\begin{gathered}
p\left\{\alpha_{1}\left[\pi_{m}\left(c_{1}\right)-x_{0}\right]-\mu_{1}\right\}+(1-p)\left\{\alpha_{2}\left[\pi_{m}\left(c_{2}\right)-x_{2}\right]-\mu_{2}\right\}-v \geq \alpha_{2}\left[\pi_{m}\left(c_{2}\right)-x_{2}\right]-\mu_{2}, \\
\alpha_{1}\left(\pi_{m}\left(c_{1}\right)-x_{0}\right)-\mu_{1} \geq 0 \\
\alpha_{2}\left[\pi_{m}\left(c_{2}\right)-x_{2}\right]-\mu_{2} \geq 0 \\
\alpha_{1} \geq \alpha_{0}
\end{gathered}
$$

\footnotetext{
${ }^{7}$ The necessity to reset the options in the money is due to the lack of further uncertainty at time $t=1$. In a slightly more general model, it would be possible to achieve the same incentives by resetting them at the money.

${ }^{8}$ For notational simplicity we have replaced the call options maximum operator by the realized observation (either zero or a positive amount) below.
} 


$$
\alpha_{2} \geq \alpha_{0}
$$

where equation (15) represents the incentive compatibility constraint at $t=0$ and (16) and (17) are respective incentive compatibility constraints after no shock and shock.

Proposition 2. The solution to problem (14) features $\alpha_{1}=\alpha_{0}$ where the optimal number of options is given by

$$
\alpha_{0}^{*}=\frac{(v / p)+\mu_{1}}{\pi_{m}\left(c_{1}\right)-x_{0}}
$$

Moreover there is zero surplus given to the workers in the shock state,

$$
\alpha_{2}\left(\pi_{m}\left(c_{2}\right)-x_{2}\right)-\mu_{2}=0
$$

Proof. As mentioned above, the options will always be reset in the shock state and there is no need to provide surplus to the workers in that state. Therefore (17) will be satisfied with equality. This gives (21). Substituting this into the initial period incentive compatibility constraint (15), this constraint becomes

$$
p\left(\alpha_{1}\left(\pi_{m}\left(c_{1}\right)-x_{0}\right)-\mu_{1}\right) \geq v .
$$

Therefore

$$
\alpha_{1}\left(\pi_{m}\left(c_{1}\right)-x_{0}\right)-\mu_{1} \geq v / p
$$

In which case the second period incentive compatibility constraint (16) after no shock is not binding. Therefore there is no need to readjust the number of options granted upward in this case to provide the requisite incentives, $\alpha_{1}=\alpha_{0}$. Clearly there is no need to provide extra surplus to the workers in the first period and therefore the first period incentive compatibility constraint then will bind:

$$
p\left(\alpha_{1}\left(\pi_{m}\left(c_{1}\right)-x_{0}\right)-\mu_{1}\right)=v .
$$

Solving this equation for $\alpha_{0}=\alpha_{1}$ then yields equation 20 .

In contrast to the stock compensation case we see that it will never be necessary to reincentivize the 
workers after the no shock scenario. The original number of options granted and the original exercise price will still provide proper motivation. However in the downward state when the shock is observed the options price will have to be reset and possibly the number granted increased. Nevertheless the workers will not earn any extra surplus in that situation.

We now consider a comparison of the surplus given to the workers in the stock compensation case with the options compensation case.

COROLLARY 4. In the options compensation case, the rent given to the workers after no shock is observed is equal to

$$
\alpha_{0}\left(\pi_{m}\left(c_{1}\right)-x_{0}\right)-\mu_{1}=v / p
$$

When stock is utilized and condition (9) is satisfied the rent given to the workers after no shock is observed is equal to

$$
s_{0}\left(\pi_{m}\left(c_{1}\right)-\pi_{m}\left(c_{2}\right)\right)-\mu_{1}=(v / p)-\mu_{2}
$$

When (10) holds, the rent given to the workers after no shock is equal to

$$
s_{0}\left(\pi_{m}\left(c_{1}\right)-\pi_{m}\left(c_{2}\right)\right)-\mu_{1}=\frac{v}{p}\left(1-\frac{\pi_{m}\left(c_{2}\right)}{\pi_{m}\left(c_{1}\right)}\right)-\mu_{1} \frac{\pi_{m}\left(c_{2}\right)}{\pi_{m}\left(c_{1}\right)}
$$

In the options compensation case, the rent given to the workers after the shock is observed is always zero. The rent given to the workers in the stock compensation case after the shock is observed is zero when condition (10) is satisfied. When condition (9) is satisfied the rent given to the workers with stock compensation is equal to

$$
s_{0} \pi_{m}\left(c_{2}\right)-\mu_{2}=\frac{(v / p) \pi_{m}\left(c_{2}\right)+\mu_{1} \pi_{m}\left(c_{2}\right)-\mu_{2} \pi_{m}\left(c_{1}\right)}{\pi_{m}\left(c_{1}\right)-\pi_{m}\left(c_{2}\right)} .
$$

Proof. Obtained by substituting the optimal solutions from corollaries 1, 2 and proposition 2.

Corollary 4 shows importantly that workers earn less surplus in the options compensation case than they earn in the stock compensation case when the shock occurs when condition (9) is satisfied. Otherwise they earn zero surplus in both cases. On the other hand workers earn positive rents after the 
no shock outcome. Nevertheless if the rent is positive in the stock compensation case, it is always less than in the options compensation case. Therefore we conclude that workers earn higher rents in upside states from options compensation than from stock, but lower rents in downside states as compared to stock compensation.

The implications of corollary 4 are important to establishing the shareholder value from the use of options compensation in the single firm case. This is recorded in the following result.

COROLlaRY 5. The value to shareholders when options are used is given by

$$
V(\text { option })=p \pi_{m}\left(c_{1}\right)+(1-p) \pi_{m}\left(c_{2}\right)-v-p \mu_{1}-(1-p) \mu_{2}
$$

This result holds because unlike stock compensation, zero surplus is given in the state that results from not committing initial effort. We can now see by comparing (23) with corollary 3 that options dominate stock compensation in the single firm case whenever condition (9) holds. Otherwise the shareholder values in the two compensation scenarios are identical.

Proposition 3. The use of options-based compensation strictly dominates the use of stock based compensation whenever condition (9) is satisfied. Otherwise, options-based compensation and stock compensation are equivalent.

Proof. Subtracting equation (23) from equation (13) gives

$$
V(\text { option })-V(\text { stock })=s_{0}^{*} \pi_{m}\left(c_{2}\right)-\mu_{2} \text {. }
$$

Thus the difference in shareholder values is exactly equal to the surplus earned by workers in the shock state. Corollary 4 shows that workers earn surplus in the shock state only when condition (9) holds. Otherwise it is zero.

This result confirms the usual intuition of optimal contracting theory in the context of our single firm model. Since options have an additional contract parameter compared to stock, they can often provide the same incentives at cheaper cost. In this case, the contracting imperfection caused by not being able to reduce long term incentives in the interim downward state case be overcome with options but not 
with stock. Absent additional considerations, there would be no need to consider stock compensation. We now explore whether this is still true when product market interaction occurs.

\section{Competition Among Firms}

In this section, we extend our model to an industry with two competing firms (indexed by $i$ and $j$ ). The key additional ingredient in the competitive situation is that the professional staff of both firms are assumed to be mobile, that is once there is information at the interim date, they will work for the highest bidder. While it is certainly true that some firms are able to get their chief executives to sign 'non-compete' clauses at the initial signing date, it is far less clear that such contractual restrictions are enforceable at lower levels, either for management or professional staff such as engineers. 9 Therefore we assume that workers are not bound to the initial firm that they sign up with.

We consider first the case where the adverse shock is firm-specific, i.e., the shocks are independent of each other. We further specify the following reduced form model of product and labor competition. The two firms start with identical technological possibilities, costs, efforts and outcomes. At the interim date, $t=1$ whether one firm, both or neither has received the shock is publicly known. As a result of this information, the firms can bid for each others employees in order to obtain an advantage in the product markets. We assume that if both firms continue using their existing workers, they compete as as a Cournot-Nash duopoly at time $t=2$. Let $\pi_{d}\left(c_{i}, c_{j}\right)$ be the Cournot-Nash duopoly profit of firm $i$ given that firm $i$ and firm $j$ have production processes described by the technological costs, $c_{i}$ and $c_{j}$, respectively. Alternatively, if one of the two firms, e.g., $i$, is successful in attracting the employees of firm $j$, then we model the product market in terms of a Stackelberg duopoly game in which the firm that attracts the workers from its rival becomes 'leader' and the firm that loses its workers becomes the 'follower'. We denote the respective profits of the leader and follower as $\pi_{s l}\left(c_{i}, c_{j}\right)$ and $\pi_{s f}\left(c_{j}, c_{i}\right)$. The Stackelberg follower firm must go into the labor market to hire new workers and compensate them sufficiently so that they expend the effort at time $t=1$.

There are several important assumptions that we make concerning the ordering of the profits in the

\footnotetext{
${ }^{9}$ A situation indicative of such competitive pressures came to light in 2005 when a key Microsoft employee, Kai-Fu Lee was lured away by Google. Microsoft attempted to invoke a non-compete clause in its contract with Lee, but Google alleged Lee spent the majority of his time in California where such clauses are not enforceable. .
} 
various duopoly situations. All of these assumptions are satisfied in the Cournot-Nash and Stackelberg models. First, we assume that it is better to be the low cost competitor in a duopoly compared to an identical cost duopoly, i.e., $\pi_{d}\left(c_{1}, c_{2}\right)>\pi_{d}\left(c_{1}, c_{1}\right)>\pi_{d}\left(c_{2}, c_{2}\right)$. Moreover, we assume that it is better to be a Stackelberg leader than a duopoly with identical cost parameters, which in turn is better than being a Stackelberg follower, $\pi_{s l}\left(c_{i}, c_{j}\right)>\pi_{d}\left(c_{i}, c_{j}\right)>\pi_{s f}\left(c_{i}, c_{j}\right)$. Finally we assume that the sum of Stackelberg profits in the two cost scenarios is sufficiently large compared to the sum of duopoly profits, namely

$$
\pi_{s l}\left(c_{1}, c_{2}\right)+\pi_{s f}\left(c_{2}, c_{1}\right)-\pi_{d}\left(c_{1}, c_{2}\right)-\pi_{d}\left(c_{2}, c_{1}\right)>\mu_{2}
$$

This latter condition can be interpreted as meaning that the total industry profit in the Stackelberg game is greater than the total industry profit in the Cournot-Nash game.

\subsection{The Bargaining Subgame}

With independent shocks, the probability that both firms do not observe the shock is $p^{2}$ and the probability that both firms observe the shock is $(1-p)^{2}$. In these two scenarios the firms are in symmetric positions as far as anticipated costs are concerned. We assume that the two firms do not bid for each others workers in these scenarios and that the workers continue to be employed by their original employer. Based on the single firm analysis the original incentives are sufficient when both firms do not observe the shock, however they may have to provide additional incentives when both observe the shock.

With probability $2 p(1-p)$ the firms are in an asymmetric situation where one firm observes the shock and the other does not. Now we consider the possibility where the firm without the shock might make a bid for the staff of the firm with the adverse shock. Because workers are a scarce resource, we model the bargaining game as one where the raiding firm must make an offer to the workers higher than its rival is willing to pay to retain them. This implies that the workers might gain some additional surplus due to competitive forces in the labor market.

Suppose that firm $j$ has no shock while firm $i$ observes a shock. First, suppose that firm $i$ has granted its employees stock compensation at the level, $s_{i}$. Therefore from the standpoint of the shareholders of firm $i$, if the firm retains its employees the residual shareholder value will be $\left(1-s_{i}\right) \pi_{d}\left(c_{2}, c_{1}\right)$, since 
it would then find itself as the high cost competitor in a duopoly. If firm $i$ were to lose its workers, it would have to go back into the labor market and hire new ones at a cost $\mu_{2}$ and would earn profit equal to $\pi_{s f}\left(c_{2}, c_{1}\right)$. Thus firm $i$ willingness-to-pay in order to retain its workers would be the difference between these two possibilities or

$$
W_{i}=\left(1-s_{i}\right) \pi_{d}\left(c_{2}, c_{1}\right)-\bar{\pi},
$$

where

$$
\bar{\pi}=\pi_{s f}\left(c_{2}, c_{1}\right)-\mu_{2}
$$

the outside option of the firm if it loses its workers. The firms existing workers could potentially demand that their total compensation be raised therefore to

$$
s_{i} \pi_{d}\left(c_{2}, c_{1}\right)+W_{i}=\pi_{d}\left(c_{2}, c_{1}\right)-\bar{\pi}
$$

This is the maximum amount that the workers can extract as compensation from the raiding firm.

Second, suppose that firm $i$ has granted its employees options in the amount $\alpha_{i}$ with exercise price $x_{i}$. Repeating the analysis above states that by retaining the employees, the shareholder value is $\pi_{d}\left(c_{2}, c_{1}\right)-\alpha_{i}\left(\pi_{d}\left(c_{2}, c_{1}\right)-x_{i}\right)$. If the firm loses its workers it must as before recruit new ones and the firm becomes a Stackelberg follower. The willingness-to-pay to retain the workers now becomes

$$
W_{i}=\pi_{d}\left(c_{2}, c_{1}\right)-\alpha_{i}\left(\pi_{d}\left(c_{2}, c_{1}\right)-x_{i}\right)-\bar{\pi}
$$

Once again, we see that the maximum amount the workers could potentially demand is

$$
\alpha_{i}\left(\pi_{d}\left(c_{2}, c_{1}\right)-x_{i}\right)+W_{i}=\pi_{d}\left(c_{2}, c_{1}\right)-\bar{\pi}
$$

This is identical with the case when stock is used for compensating the workers of the firm with the adverse shock. Therefore the method of compensation does not matter as a form of defensive tactics against a raid from the rival firm. 
Next we consider the impact of compensation choice on the offensive strategy of the raiding firm, $j$. Suppose that firm $j$ has used stock compensation at the level $s_{j}$. If it is able to attract the workers of firm $i$, its profit will increase by $\pi_{s l}\left(c_{1}, c_{2}\right)-\pi_{d}\left(c_{1}, c_{2}\right)$. Hence given the fact that this increment must be shared with the firms existing workers firm js maximum willingness to pay to attract its rivals workers is

$$
W_{j}=\left(1-s_{j}\right)\left(\pi_{s l}\left(c_{1}, c_{2}\right)-\pi_{d}\left(c_{1}, c_{2}\right)\right)
$$

Therefore if $W_{j}>\pi_{d}\left(c_{2}, c_{1}\right)+W_{i}$, firm $j$ will be willing to pay more than firm $i$ can afford to retain its workers. This implies that in any equilibrium in which stock level $s_{j}=s_{0}$ is chosen initially this critical condition becomes

$$
s_{0}<\frac{\pi_{s l}\left(c_{1}, c_{2}\right)-\pi_{d}\left(c_{1}, c_{2}\right)-\pi_{d}\left(c_{2}, c_{1}\right)+\bar{\pi}}{\pi_{s l}\left(c_{1}, c_{2}\right)-\pi_{d}\left(c_{1}, c_{2}\right)} .
$$

Similarly when firm $j$ has chosen stock option compensation the maximum willingness to pay to attract the workers of its rival is

$$
W_{j}=\left(1-\alpha_{j}\right)\left(\pi_{s l}\left(c_{1}, c_{2}\right)-\pi_{d}\left(c_{1}, c_{2}\right)\right) \text {. }
$$

Now when $W_{j}<s_{i} \pi_{d}\left(c_{2}, c_{1}\right)+W_{i}$, firm $j$ cannot afford to attract the workers. Therefore the critical condition for option compensation $\alpha_{j}=\alpha_{0}$ to provide insufficient incentives to attract the rival employees becomes

$$
\alpha_{0}>\frac{\pi_{s l}\left(c_{1}, c_{2}\right)-\pi_{d}\left(c_{1}, c_{2}\right)-\pi_{d}\left(c_{2}, c_{1}\right)+\bar{\pi}}{\pi_{s l}\left(c_{1}, c_{2}\right)-\pi_{d}\left(c_{1}, c_{2}\right)}
$$

Our results on the subgame bargaining game can now be summarized in the following proposition.

Proposition 4. In any subgame in which firm $i$ receives the shock while firm $j$ does not, firm $i$ loses its workers to firm $j$ and its workers receive total compensation equal to $\pi_{d}\left(c_{2}, c_{1}\right)-\bar{\pi}$ from their new employer whenever firm $j$ uses stock compensation $s_{0}$ for its own workers and $s_{0}<f$ where

$$
f=\frac{\pi_{s l}\left(c_{1}, c_{2}\right)-\pi_{d}\left(c_{1}, c_{2}\right)-\pi_{d}\left(c_{2}, c_{1}\right)+\bar{\pi}}{\pi_{s l}\left(c_{1}, c_{2}\right)-\pi_{d}\left(c_{1}, c_{2}\right)}
$$

In the same subgame firm $i$ is able to retain its workers by increasing their compensation to the level 
$\left(1-\alpha_{0}\right)\left(\pi_{s l}\left(c_{1}, c_{2}\right)-\pi_{d}\left(c_{1}, c_{2}\right)\right.$ only if firm $j$ uses option compensation at the level $\alpha_{0}$ and $\alpha_{0}>f$.

The critical condition, $f$, can be interpreted as the total gain by the entire industry from converting the structure from a duopoly to a Stackelberg leader/follower situation, divided by the private gain of the stronger firm in that industry. Equation (24) states that when the fraction of the single firm gain extracted by existing workers of firm $i$ is sufficiently less than the gain of the entire industry, the industry will be transformed. On the other hand if options are used and (25) holds then dilution of the gains are too great and the industrial structure remains at the status quo.

Notice the difference between conditions (24) and (25). We are assuming that the number of shares, $s_{0}$, required for provision of incentives is less than the critical amount on the right hand side of (24), while the number of shares obtained by exercising options, $\alpha_{0}$, is above this same amount. This is motivated by the fact that setting the initial option exercise price at the money requires a substantially larger share allocation for incentive purposes. Indeed $s_{0}$ is significantly less than $\alpha_{0}$ whenever options exercise prices are at the money. This also conforms to the data mentioned in the introduction on the higher proportion of ownership concentration in employees with stock option plans. In other words, we are assuming that the potential dilution due to option compensation is significantly larger than that of stock compensation. If either (24) or (25) are not satisfied, then there are no strategic considerations in the use of stock v. options compensation and we are essentially back to the single firm analysis.

We now consider the three respective choices of compensation in a game theoretic situation (stockstock, option-stock and option-option). Firms choose their compensation simultaneously at the initial time.

\subsection{Stock Compensation}

We now derive the value to shareholders when both firms choose stock compensation. To reduce the amount of notation without losing any of the economic insights, we henceforth assume that no further effort is required of workers in either firm when they do not observe a shock, i.e., we set $\mu_{1}=0$ in the sequel. Obviously, since no further effort is required, it is never necessary to reincentivize workers without the shock, the only possibility for a binding incentive compatibility constraint is when the firm realizes the adverse shock. But here when the workers are raided by the rival firm without the 
shock, there is again no need for reincentivization. The only situation occurs when both firms realize the shock. Therefore, when the following condition, analogous to (9) is satisfied, we know that the downward interim incentive compatibility condition is not binding:

$$
v / p>\mu_{2} \frac{\pi_{s l}\left(c_{1}, c_{2}\right)}{\pi_{d}\left(c_{2}, c_{2}\right)}
$$

This assumption is maintained throughout the analysis of the competitive situation.

Define the following matrix, $A_{s s}$, representing the profit of firm $i$ in the various subgames when both $i$ and $j$ use stock. In this matrix, the rows represent the two outcomes, no shock and shock for the rival firm, $j$, and the columns represent the states of no shock and shock for the firm $i$.

$$
A_{s s}=\left(\begin{array}{cc}
\left(1-s_{0}\right) \pi_{d}\left(c_{1}, c_{1}\right) & \bar{\pi} \\
\left(1-s_{0}\right) \pi_{s l}\left(c_{1}, c_{2}\right)-\pi_{d}\left(c_{2}, c_{1}\right)+\bar{\pi} & \left(1-s_{0}\right) \pi_{d}\left(c_{2}, c_{2}\right)
\end{array}\right) .
$$

Similarly the outcomes from the standpoint of workers in firm $i$ in the respective states can be written as $B_{s s}$ where

$$
B_{s s}=\left(\begin{array}{cc}
s_{0} \pi_{d}\left(c_{1}, c_{1}\right) & \pi_{d}\left(c_{2}, c_{1}\right)-\bar{\pi} \\
s_{0} \pi_{s l}\left(c_{1}, c_{2}\right) & s_{0} \pi_{d}\left(c_{2}, c_{2}\right)-\mu_{2}
\end{array}\right)
$$

Define further the vectors

$$
\bar{p}=\left(\begin{array}{c}
p \\
1-p
\end{array}\right)
$$

and

$$
\bar{r}_{s s}^{\top}=\left(\pi_{d}\left(c_{2}, c_{1}\right)-\bar{\pi} \quad s_{0} \pi_{d}\left(c_{2}, c_{2}\right)-\mu_{2}\right)
$$

The elements of this vector represent the respective outcomes when the workers of firm $i$ are bid away by the rival, firm $j$, and remain with firm $i$ respectively.

We can then define the problem of choosing an optimal level of stock compensation when the rival also uses this compensation strategy:

$$
\max _{s_{0}} \bar{p}^{\top} A_{s s} \bar{p}
$$


subject to

$$
\bar{p}^{\top} B_{s s} \bar{p}-v \geq \bar{r}_{s s}^{\top} \bar{p}
$$

In problem (32), we have used the facts that the interim incentive compatibility constraints are nonbinding. Since the initial incentive compatibility constraint is binding, we can solve for the shareholder value as the total organizational surplus minus the expected costs of effort:

$$
V(\text { stock } \mid \text { stock })=\bar{p}^{\top}\left(A_{s s}+B_{s s}\right) \bar{p}-v-\bar{r}_{s s}^{\top} \bar{p}
$$

Expanding this expression we find that the shareholders of firm $i$ realize the following net payoff in a (stock,stock) equilibrium:

$$
\begin{aligned}
V(\text { stock } \mid \text { stock })= & p^{2} \pi_{d}\left(c_{1}, c_{1}\right)+p(1-p) \pi_{d}\left(c_{2}, c_{1}\right)+(1-p) p\left[\pi_{s l}\left(c_{1}, c_{2}\right)-\pi_{d}\left(c_{2}, c_{1}\right)+\bar{\pi}\right]+(1-p)^{2} \pi_{d}\left(c_{2}, c_{2}\right) \\
& -v-(1-p)^{2} \mu_{2}-p\left[\pi_{d}\left(c_{2}, c_{1}\right)-\bar{\pi}\right]-(1-p)\left[s_{0}^{*} \pi_{d}\left(c_{2}, c_{2}\right)-\mu_{2}\right],
\end{aligned}
$$

where

$$
s_{0}^{*}=\frac{p^{2}\left[\pi_{d}\left(c_{2}, c_{1}\right)-\bar{\pi}\right]+v-p(1-p) \mu_{2}}{p^{2} \pi_{d}\left(c_{1}, c_{1}\right)+(1-p) p \pi_{s l}\left(c_{1}, c_{2}\right)-p(1-p) \pi_{d}\left(c_{2}, c_{2}\right)} .
$$

There are two differences in the competitive environment that differ from the firm payoff in the single firm case. Both pertain to the implications of winding up in the down state when the competitor has favorable news. Firstly the firm loses its workers and so it only receives the outside option in this situation. Secondly the workers are bid away by the competitive firm and paid the potential duopoly profit net of the outside option they could have received by their original employer. This potential profit leads to increased rent that the firm has to bear ex ante. Therefore both effects wind up hurting the firm.

Equation (35) reflects the share that must be allocated to the initial staff to provide maximum incentives so that the firm either winds up in a duopoly with an equally strong competitor, or as a Stackelberg leader. 


\subsection{Asymmetric Strategies}

Suppose now that firm $i$ switches to stock option compensation with initial level $\alpha_{0}$ and exercise price $x_{0}$, but firm $j$ remains using pure stock compensation. As previously firm $i$ will again lose its workers when it observes the shock but firm $j$ does not. When firm $i$ selects options, its shareholder value in the various states becomes:

$$
A_{o s}=\left(\begin{array}{cc}
\pi_{d}\left(c_{1}, c_{1}\right)-\alpha_{0}\left[\pi_{d}\left(c_{1}, c_{1}\right)-x_{0}\right] & \bar{\pi} \\
\pi_{d}\left(c_{1}, c_{2}\right)-\alpha_{0}\left[\pi_{d}\left(c_{1}, c_{2}\right)-x_{0}\right] & \pi_{d}\left(c_{2}, c_{2}\right)-\alpha_{2}\left[\pi_{d}\left(c_{2}, c_{2}\right)-x_{2}\right]
\end{array}\right)
$$

As in the previous case, because firm $j$ uses stock, firm $i$ loses its staff when it has the adverse shock and firm $j$ does not. However, unlike the previous case, firm $i$ is unable to attract the workers of firm $j$ when it does not have the shock. Worker compensation is

$$
B_{o s}=\left(\begin{array}{cc}
\alpha_{0}\left[\pi_{d}\left(c_{1}, c_{1}\right)-x_{0}\right] & \pi_{d}\left(c_{2}, c_{1}\right)-\bar{\pi} \\
\alpha_{0}\left[\pi_{d}\left(c_{1}, c_{2}\right)-x_{0}\right] & \alpha_{2}\left[\pi_{d}\left(c_{2}, c_{2}\right)-x_{2}\right]-\mu_{2}
\end{array}\right)
$$

Worker reservation wages are also given by:

$$
r_{o s}^{\top}=\left(\pi_{d}\left(c_{2}, c_{1}\right)-\bar{\pi} \quad \alpha_{2}\left[\pi_{d}\left(c_{2}, c_{2}\right)-x_{2}\right]-\mu_{2}\right)
$$

Therefore the following principal-agent problem is solved by firm $i$ :

$$
\max _{\alpha_{0}, \alpha_{2}} \bar{p}^{\top} A_{o s} \bar{p}
$$

subject to

$$
\begin{gathered}
\bar{p}^{\top} B_{o s} \bar{p}-v \geq r_{o s}^{\top} \bar{p} \\
\alpha_{2}\left[\pi_{d}\left(c_{2}, c_{2}\right)-x_{2}\right]-\mu_{2} \geq 0 .
\end{gathered}
$$

In problem (39), the initial incentive compatibility condition (40) is binding as in the previous case. But now the interim incentive compatibility condition (41) in the adverse state will also be binding 
since originally issued options are underwater.

Since both (40) and (41) are binding, we can substitute both with equality and we obtain the following expression for the shareholders of firm $i$ 's payoff:

$$
\begin{aligned}
V(\text { option } \mid \text { stock })= & p^{2} \pi_{d}\left(c_{1}, c_{1}\right)+p(1-p) \pi_{d}\left(c_{2}, c_{1}\right)+(1-p) p \pi_{d}\left(c_{1}, c_{2}\right) \\
& +(1-p)^{2} \pi_{d}\left(c_{2}, c_{2}\right)-v-(1-p)^{2} \mu_{2}-p\left[\pi_{d}\left(c_{2}, c_{1}\right)-\bar{\pi}\right] .
\end{aligned}
$$

It is instructive to contrast the firm's payoff here in equation (42) with that of (34). In the symmetric stock case, firm $i$ is able to attract the rival workers and become a Stackelberg leader when it does not realize the shock but its rival does. But the expected compensation, $(1-p) p\left[\pi_{d}\left(c_{2}, c_{1}\right)-\bar{\pi}\right]$, paid to the rival workers must be subtracted out of the organizational surplus in this case, and it coincides exactly with the surplus obtained in the opposite state where firm $i$ loses its workers to firm $j$. In the asymmetric case firm $i$ never becomes a Stackelberg leader and the organizational surplus always consists of the duopoly profits. Notice that in both relations - in contrast with the single firm case - the workers do get non-zero rents. The term $p\left[\pi_{d}\left(c_{2}, c_{1}\right)-\bar{\pi}\right]$ which occurs in both equations represents the increase in compensation when the workers shirk but the rival firm gets good news and they threaten to leave unless they receive all the profit net of the outside option. This is due to the necessity of increasing their compensation to prevent them from being bid away by the rival firm when the rival's interim news is good.

We can now take the results of (34) along with (42) together to solve for a sufficient condition for a pure strategy Nash equilibrium where both firms in a duopoly utilize stock compensation.

Proposition 5. Both firms in competition will choose a pure strategy equilibrium involving the use of stock if $V$ (stock|stock) $>V$ (option|stock) or, equivalently, if

$$
\theta \equiv p\left[\pi_{s l}\left(c_{1}, c_{2}\right)-\pi_{d}\left(c_{1}, c_{2}\right)-\pi_{d}\left(c_{2}, c_{1}\right)+\bar{\pi}\right]>s_{0}^{*} \pi_{d}\left(c_{2}, c_{2}\right)-\mu_{2}
$$

where $s_{0}^{*}$ is defined by equation (35).

Therefore we have found the possibility that pure stock compensation can survive if the rival firm uses stock compensation. In similarity with the single firm case stock compensation yields rents to the 
workers that cannot be adjusted. However, there is a benefit from pure stock compensation that is not present in the single firm case. This is due to the possibility that the required shares allocated to the workers is lower than what is required under option compensation. Hence the firm has a higher residual value with which to compete for the workers of a rival firm when that firm has interim negative news (the adverse shock). If this possibility of market leadership is significantly better than either duopoly possibility then the firm will stay with stock compensation when its rival employs the same.

\subsection{Option Compensation}

In the final case, we suppose that both firms choose stock option compensation. In this case, firm $i$ is not at risk from losing its employees although it does have to increase their compensation above the zero rent situation given by merely resetting the exercise price. Firm $i$ solves the following principal-agent problem at $t=0$ taking its rivals equilibrium strategy of $\alpha_{0}^{*}$ as given:

$$
\max _{\alpha_{0}, \alpha_{2}} \bar{p}^{\top} A_{o o} \bar{p}
$$

subject to

$$
\begin{gathered}
\bar{p}^{\top} B_{o o} \bar{p}-v \geq \bar{r}_{o o}^{\top} \bar{p} \\
\alpha_{2}\left[\pi_{d}\left(c_{2}, c_{1}\right)-x_{2}\right]-\mu_{2} \geq 0,
\end{gathered}
$$

where

$$
A_{o o}=\left(\begin{array}{cc}
\pi_{d}\left(c_{1}, c_{1}\right)-\alpha_{0}\left[\pi_{d}\left(c_{1}, c_{1}\right)-x_{0}\right] & \pi_{d}\left(c_{2}, c_{1}\right)-\left(1-\alpha_{0}^{*}\right)\left[\pi_{s l}\left(c_{1}, c_{2}\right)-\pi_{d}\left(c_{1}, c_{2}\right)\right] \\
\pi_{d}\left(c_{1}, c_{2}\right)-\alpha_{0}\left[\pi_{d}\left(c_{1}, c_{2}\right)-x_{0}\right] & \pi_{d}\left(c_{2}, c_{2}\right)-\alpha_{2}\left[\pi_{d}\left(c_{2}, c_{2}\right)-x_{2}\right]
\end{array}\right)
$$

and

$$
B_{o o}=\left(\begin{array}{cc}
\alpha_{0}\left[\pi_{d}\left(c_{1}, c_{1}\right)-x_{0}\right] & \left(1-\alpha_{0}^{*}\right)\left[\pi_{s l}\left(c_{1}, c_{2}\right)-\pi_{d}\left(c_{1}, c_{2}\right)\right]-\mu_{2} \\
\alpha_{0}\left[\pi_{d}\left(c_{1}, c_{2}\right)-x_{0}\right] & \alpha_{2}\left[\pi_{d}\left(c_{2}, c_{2}\right)-x_{2}\right]-\mu_{2}
\end{array}\right),
$$

and

$$
\bar{r}_{o o}^{\top}=\left(\left(1-\alpha_{0}^{*}\right)\left[\pi_{s l}\left(c_{1}, c_{2}\right)-\pi_{d}\left(c_{1}, c_{2}\right)\right]-\mu_{2} \quad \alpha_{2}\left[\pi_{d}\left(c_{2}, c_{2}\right)-x_{2}\right]-\mu_{2}\right) .
$$


Since both (45) and (46) are satisfied with equality, these can be substituted into (44) to yield the following payoff to shareholders of firm $i$ :

$$
\begin{aligned}
V(\text { option|option })= & p^{2} \pi_{d}\left(c_{1}, c_{1}\right)+p(1-p) \pi_{d}\left(c_{2}, c_{1}\right)+(1-p) p \pi_{d}\left(c_{1}, c_{2}\right)+(1-p)^{2} \pi_{d}\left(c_{2}, c_{2}\right) \\
& -v-(1-p) \mu_{2}-p\left\{\left(1-\alpha_{0}^{*}\right)\left[\pi_{s l}\left(c_{1}, c_{2}\right)-\pi_{d}\left(c_{1}, c_{2}\right)\right]-\mu_{2}\right\} .
\end{aligned}
$$

The firm payoff in this case has a similar interpretation to that of equation (42). The firm never goes out of business by losing its workers to the rival. However there is a rent that must be paid to the workers to prevent them from being bid away.

The final case to consider is where firm $i$ switches to pure stock compensation but firm $j$ remains using stock option compensation. Firm $i$ solves the following principal-agent problem:

$$
\max _{s_{0}} \bar{p}^{\top} A_{s o} \bar{p}
$$

subject to

$$
\bar{p}^{\top} B_{s o} \bar{p}-v \geq \bar{r}_{s o}^{\top} p
$$

where the respective payoff matrices are defined as

$$
\begin{gathered}
A_{s o}=\left(\begin{array}{cc}
\left(1-s_{0}\right) \pi_{d}\left(c_{1}, c_{1}\right) & \pi_{d}\left(c_{2}, c_{1}\right)-\left(1-\alpha_{0}^{*}\right)\left[\pi_{s l}\left(c_{1}, c_{2}\right)-\pi_{d}\left(c_{1}, c_{2}\right)\right] \\
\left(1-s_{0}\right) \pi_{s l}\left(c_{1}, c_{2}\right)-\pi_{d}\left(c_{2}, c_{1}\right)+\bar{\pi} & \left(1-s_{0}\right) \pi_{d}\left(c_{2}, c_{2}\right)
\end{array}\right), \\
B_{s o}=\left(\begin{array}{cc}
s_{0} \pi_{d}\left(c_{1}, c_{1}\right) & \left(1-\alpha_{0}^{*}\right)\left[\pi_{s l}\left(c_{1}, c_{2}\right)-\pi_{d}\left(c_{1}, c_{2}\right)\right]-\mu_{2} \\
s_{0} \pi_{s l}\left(c_{1}, c_{2}\right) & s_{0} \pi_{d}\left(c_{2}, c_{2}\right)-\mu_{2}
\end{array}\right), \\
\bar{r}_{s o}^{\top}=\left(\begin{array}{ll}
\left(1-\alpha_{0}^{*}\right)\left[\pi_{s l}\left(c_{1}, c_{2}\right)-\pi_{d}\left(c_{1}, c_{2}\right)\right]-\mu_{2} & \left.s_{0} \pi_{d}\left(c_{2}, c_{2}\right)-\mu_{2}\right) .
\end{array}\right.
\end{gathered}
$$


The payoff to the shareholders of $i$ is then:

$$
\begin{array}{r}
V(\text { stock|option })=p^{2} \pi_{d}\left(c_{1}, c_{1}\right)+p(1-p) \pi_{d}\left(c_{2}, c_{1}\right)+(1-p) p\left[\pi_{s l}\left(c_{1}, c_{2}\right)-\pi_{d}\left(c_{2}, c_{1}\right)+\bar{\pi}\right]+(1-p)^{2} \pi_{d}\left(c_{2}, c_{2}\right) \\
-v-(1-p) \mu_{2}-p\left\{\left(1-\alpha_{0}^{*}\right)\left[\pi_{s l}\left(c_{1}, c_{2}\right)-\pi_{d}\left(c_{1}, c_{2}\right)\right]-\mu_{2}\right\}-(1-p)\left[s_{0}^{* *} \pi_{d}\left(c_{2}, c_{2}\right)-\mu_{2}\right]
\end{array}
$$

where

$$
s_{0}^{* *}=\frac{p^{2}\left\{\left(1-\alpha_{0}^{*}\right)\left[\pi_{s l}\left(c_{1}, c_{2}\right)-\pi_{d}\left(c_{1}, c_{2}\right)\right]-\mu_{2}\right\}+v-p(1-p) \mu_{2}}{p^{2} \pi_{d}\left(c_{1}, c_{1}\right)+(1-p) p \pi_{s l}\left(c_{1}, c_{2}\right)-p(1-p) \pi_{d}\left(c_{2}, c_{2}\right)} .
$$

Equation (57) corresponds with (35). Now the firm in question has the possibility of becoming a Stackelberg leader; however it suffers rent to its own workers in the down state. Equation (57) represents the share necessary to provide ex ante incentives to the workers when the rival chooses option compensation.

As before, comparing equations (50) and (56) yields the necessary conditions for a pure strategy equilibrium in which both rival firms compete by offering options to their professional staffs.

Proposition 6. The use of option compensation by both firms in a duopoly setting is a Nash equilibrium if $V$ (option|option) $>V($ stock|option $)$ or, equivalently, if

$$
s_{0}^{* *} \pi_{d}\left(c_{2}, c_{2}\right)-\mu_{2}>p\left[\pi_{s l}\left(c_{1}, c_{2}\right)-\pi_{d}\left(c_{1}, c_{2}\right)-\pi_{d}\left(c_{2}, c_{1}\right)+\bar{\pi}\right]=\theta
$$

where $s^{* *}$ is given by equation (57), and the equilibrium quantity of options by is given by $\alpha_{0}^{*}$ defined by

$$
\alpha_{0}^{*}=\frac{p^{2} \pi_{s l}\left(c_{1}, c_{2}\right)-p^{2} \pi_{d}\left(c_{1}, c_{2}\right)+v-p^{2} \mu_{2}}{p^{2} \pi_{s l}\left(c_{1}, c_{2}\right)+p^{2} \pi_{d}\left(c_{1}, c_{1}\right)+p(1-2 p) \pi_{d}\left(c_{1}, c_{2}\right)-p x_{0}} .
$$

Proof. The equilibrium condition for $\alpha_{0}^{*}$ is obtained by setting both incentive compatibility conditions, (45) and (46), as equalities and solving for $\alpha_{0}$ with $\alpha_{0}=\alpha_{0}^{*}$.

Generally speaking which of the two symmetric pure strategy equilibria occurs depends on the magnitude of the term $\theta=p\left[\pi_{s l}\left(c_{1}, c_{2}\right)-\pi_{d}\left(c_{1}, c_{2}\right)-\pi_{d}\left(c_{2}, c_{1}\right)+\pi_{s f}\left(c_{2}, c_{1}\right)-\mu_{2}\right]$. This is greater the greater is the likelihood that initial effort does not result in an adverse shock. It is also larger in product market situations where the industrial payoff to Stackelberg leadership is substantially larger than 
the sum of both duopoly situations. We know that where there are technological 'races' the payoff to establishing either explicit market dominance (via patents) or implicitly by locking up the most valuable and innovative professional staffs is very large. This by itself would tend to indicate a greater likelihood of realizing the stock-based compensation equilibrium. However along with such technology-driven races also often arises a greater need for frequent revisions of plans and adjustments. This indicates that $p$ may be lower. This has a countervailing effect. Now one would tend to see situations where firms optimally respond by incentivizing workers with options.

There is also the possibility of an asymmetric pure strategy equilibrium in which one firm uses stock compensation and its rival uses stock option compensation. This occurs when both the conditions in propositions 5 and 6 are violated. Proposition 7 characterizes this form of equilibrium.

Proposition 7. The use of option compensation by one firm and stock by its rival in a duopoly setting is a Nash equilibrium if neither (43) nor (58) holds. In this case the firm that uses stock grants $s_{0}^{* *}$ shares satisfying (57), with the equilibrium quantity of options given by $\alpha_{0}=\alpha_{0}^{* *}$ defined by

$$
\alpha_{0}^{* *}=\frac{p^{2}\left[\pi_{d}\left(c_{2}, c_{1}\right)-\bar{\pi}\right]+v}{p^{2} \pi_{d}\left(c_{1}, c_{1}\right)+p(1-p) \pi_{d}\left(c_{1}, c_{2}\right)-p x_{0}} .
$$

Proof. The equilibrium condition for $\alpha_{0}^{* *}$ is obtained by setting both incentive compatibility conditions, (40) and (41), as equalities and solving for $\alpha_{0}$.

\subsection{Uniqueness}

Propositions 5 and 6 provide the conditions under which either type of symmetric Nash equilibrium can occur. As is clear from examining conditions (43) and (58) the key determinant will be how $s^{* *}$, the optimal stock incentives when a rival uses options is related to $s^{*}$, the optimal stock compensation response when a rival uses stock. We show below in proposition 8 that $s^{* *}<s^{*}$, which then implies that the Nash equilibrium form is always unique. The reason that $s^{* *}<s^{*}$ is due to the payoff received by the workers in the downward state where their initial employer receives the shock. When the rival uses options, it has to give its own existing workers such a large share of the potential enhanced profits that it cannot afford to recruit additional staff. Hence the employees do not benefit as much from shirking 
as when the rival firm uses stock. On the other hand, when the rival firm uses stock compensation, it can afford to and will therefore pay the duopoly profit to attract them and this makes ex ante shirking more profitable. As a result their initial employer has to pay a higher level of stock compensation to motivate the initial effort. We prove this formally in the following proposition.

Proposition 8. The equilibrium in the industrial competition game is unique and is determined by the following respective conditions.

(a) If condition (43) holds, (stock, stock) is the unique Nash equilibrium.

(b) If condition (58) holds, (option,option) is the unique Nash equilibrium.

(c) If neither (43) nor (58) holds, the equilibrium is asymmetric and one firm chooses option compensation while the other firm chooses stock compensation.

Proof. Let $\alpha_{0}^{*}$ be the equilibrium number of call options granted if one firm chooses option compensation in the equilibrium. From the requirement that workers are not bid away when the firm uses options, 25), we have

$$
\alpha_{0}^{*}>\frac{\pi_{s l}\left(c_{1}, c_{2}\right)-\pi_{d}\left(c_{1}, c_{2}\right)-\pi_{d}\left(c_{2}, c_{1}\right)+\bar{\pi}}{\pi_{s l}\left(c_{1}, c_{2}\right)-\pi_{d}\left(c_{1}, c_{2}\right)} .
$$

It follows from the above inequality that

$$
1-\alpha_{0}^{*}<\frac{\pi_{d}\left(c_{2}, c_{1}\right)-\bar{\pi}}{\pi_{s l}\left(c_{1}, c_{2}\right)-\pi_{d}\left(c_{1}, c_{2}\right)}
$$

Substituting this inequality into equation (57) yields

$$
s^{* *}<\frac{p^{2}\left[\pi_{d}\left(c_{2}, c_{1}\right)-\bar{\pi}-\mu_{2}\right]+v-p(1-p) \mu_{2}}{p^{2} \pi_{d}\left(c_{1}, c_{1}\right)+(1-p) p \pi_{s l}\left(c_{1}, c_{2}\right)-p(1-p) \pi_{d}\left(c_{2}, c_{2}\right)}<s^{*},
$$

where the second inequality follows from equation (35) and $\mu_{2}>0$. Hence, if condition (43) holds, condition (58) cannot hold. However, if condition (43) does not hold, condition (58) may or may not hold. 


\section{Implications and Extensions}

In this section we explore the implications of our model and then consider extending the analysis to situations where shocks are imperfectly correlated across firms, early vesting, other forms of contingent compensation contracting and accounting issues surrounding compensation.

\subsection{Market Structure}

The analysis of the previous section shows that the implications of our model for compensation are first and foremost driven by the nature of industry competition in a duopoly. In this respect, the total gains from moving from Cournot-Nash to Stackelberg in any asymmetric cost situation are given by

$$
\theta / p=\pi_{s l}\left(c_{1}, c_{2}\right)+\pi_{s f}\left(c_{2}, c_{1}\right)-\pi_{d}\left(c_{1}, c_{2}\right)-\pi_{d}\left(c_{2}, c_{1}\right)-\mu_{2}
$$

The question relates to the magnitude of this quantity. When the respective cost differences are not large between two rivals and product demands are fairly elastic there is not much to be gained in conversion to Stackelberg structure and therefore the potential industry gains are slim. Since this term shows up in the numerator of the critical condition $(26)$, this means that $f$ is near zero and the conditions for aggressive behavior in the labor market is not satisfied, independent of whether stock or options are used. Hence the analysis essentially reverts to the case where firms choose their compensation policies independent of one another and options dominate stock. This mimics what happens when there is only a single monopolistic firm in an industry.

When $\theta / p$ is still near zero but (24) and (25) are both satisfied (due to the significance of private gains to the leading firm in a Stackelberg industry) then proposition 6 applies and it is still the case that both firms choose options in equilibrium. Therefore we conclude that when potential industry gains are limited, firms act the same way in competition that they would do as monopolists, already dominating an industry.

As $\theta / p$ increases due to increased benefits assuming that the necessary conditions for disparate offensive strategies are satisfied, (24) and (25), we reach a point where the conditions of proposition 7 are satisfied and firms select different strategies. One firm selects stock options and its rival selects 
pure stock compensation.

As $\theta / p$ increases further and the sufficient condition for private gains to becoming a Stackelberg leader remain satisfied, then firms would wind up as in proposition 5 and both would select stock to compensate their workers. In this situation we would also expect the most aggressive bidding when one firm sees weakness in its rival.

Since industry conditions do not remain constant over time, our model predicts a form of 'lifecycle' compensation practices in an industry. With a single monopolistic firm, options would be used; later after entry and increased competition one would expect to see heterogeneous policies; when an industry shakeout has occurred and there are two very aggressive competitors, both would shift to the use of stock. In the limiting case where one firm could drive its rival completely out of business by recruiting its workers, then the surviving firm becomes a monopolist and then switches back to the use of options compensation.

\subsection{Correlated Shocks}

We now focus on the implications of $p$, the probability of not observing a shock and extend the model to the case of correlated shocks between the firm and its rival. In this more general case, the structure of the sufficient conditions for existence of the pure strategy equilibria is preserved, although with a change in the interpretation of the probability, $p$. Recall the key state in the model occurs when the firm is in a strong position having received no adverse news, while the rival firm has the shock. The threshold value, $\theta$, that governs the nature of the equilibrium contained in (43) as well as (58) can be written as

$$
\theta=\operatorname{Prob}(i \text { no shock } \mid j \text { shock })\left[\pi_{s l}\left(c_{1}, c_{2}\right)-\pi_{d}\left(c_{2}, c_{1}\right)-\pi_{d}\left(c_{1}, c_{2}\right)+\pi_{s f}\left(c_{2}, c_{1}\right)-\mu_{2}\right]
$$

For the independent case the conditional probability, $\operatorname{Prob}(i$ no shock $\mid j$ shock $)$ is equal to $p$.

Now, as the possible shocks to both firms become positively correlated, this means that this conditional probability is reduced and therefore $\theta$ decreases. From the results of propositions 5 and 6 this makes it more likely that the option-based equilibrium will obtain. Intuitively, it is less likely that news is asymmetric between the firms and so it is not necessary to adopt a tougher stance in order to 
profit from the demise of a rival firm. From this, we can conclude that if the economic environment is one where all firms are subject to similar shocks, we would expect a greater prevalence of options compensation.

On the other hand, if shocks are negatively correlated, then the conditional probability embodied in $\theta$ increases, eventually to unity under perfect negative correlation. Now $\theta$ also increases and it becomes more beneficial to profit from the difficulties of a rival firm. As a result stock compensation would tend to predominate. Therefore we can conclude that the macroeconomic climate and the degree of competitiveness play a significant role in determining the nature of stock-based compensation programs.

\subsection{Vesting}

We have heretofore assumed that workers at the firms are not vested with either options or stock until the second period cash flow observation is observed. If they stay with the firm they are guaranteed compensation conditional on the outcome of the relevant compensation equilibrium. However we assumed that when they voluntarily take a competing offer from the rival they give up their compensation rights completely.

Now consider what would happen if the firm were to vest their workers immediately so that they would retain stock and options originally promised even if they should jump to the rival. First consider the use of stock compensation. Then firm $i$ obtains net profit $\left(1-s_{i}\right) \pi_{d}\left(c_{2}, c_{1}\right)$ if the workers remain, as before. On the other hand, if they jump to the rival, the firm obtains $\left(1-s_{i}\right) \pi_{s f}\left(c_{2}, c_{1}\right)-\mu_{2}$, which is strictly less than without early vesting. Therefore the willingness to pay by firm $i$ is

$$
W_{i}=\left(1-s_{i}\right)\left(\pi_{d}\left(c_{2}, c_{1}\right)-\pi_{s f}\left(c_{2}, c_{1}\right)\right)-\mu_{2}
$$

For the workers to be bid away from the rival firm, it is only necessary that its willingness to pay, $W_{j}$ be

$$
W_{j}>s_{i} \pi_{s f}\left(c_{2}, c_{1}\right)+W_{i}
$$


or

$$
W_{j}>\left(1-s_{i}\right)\left(\pi_{d}\left(c_{2}, c_{1}\right)-\pi_{s f}\left(c_{2}, c_{1}\right)\right)+s_{i} \pi_{s f}\left(c_{2}, c_{1}\right)-\mu_{2}
$$

Since $W_{j}$ for the rival firm is the same as before, it follows that this condition is much easier to satisfy than before, whether a firm uses stock or options. Intuitively vesting stock allows the rival to attract the workers more cheaply because the original firm is still paying most of the original compensation.

When the original employer uses options, its willingness to pay is unaffected whether the options vest or not. The reason is that when the firm realizes the adverse shock, the options are underwater and therefore if the workers leave there is no reason to reset the exercise price and they remain underwater.

Therefore if the firm were to utilize vesting for its compensation policies, this creates a divergence between defensive practices for retaining workers. In fact it makes it unlikely that the firm will be able to retain its stock-compensated workers after the shock. This implies that not vesting stock immediately is an important ingredient of an optimal compensation policy.

\subsection{State-contingent Stock Compensation}

The major benefit of options compensation in this model derives from the ability to utilize statecontingent compensation features to simultaneously increase productive efficiency and reduce excess rent. On the other hand, in the competitive market the use of such compensation creates the possibility of dilution. This raises the issue of whether instead to use stock compensation that is only granted (or vested) at a later date based on intermediate outcomes. An example of this is given by the changes to the compensation package of GEs CEO, Jeffrey Immelt, when he ascended to his position in 2003.10 In fact it is true that state-contingent stock compensation would dominate both options as well as unconditional stock grants in the model of product market competition. This is because the maximum amount of stock granted will never be larger than the unconditional stock grant, so there is lower potential dilution; and at the same time the stock can be granted at only the minimum level to provide incentives in the second period. Thus, all potential rent is extracted.

However, the use of state-contingent stock compensation is very sensitive to an assumption that the

\footnotetext{
${ }^{10}$ Specifically the GE board awarded Immelt 250,000 performance units. One-half would vest at the end of five years only if cash flow from operations grew at least by 10 percent each year; the other half would vest only if the GE stock price performance exceeded that of the S\&P 500 index.
} 
intermediate state (shock or no shock) is a contractible event. In order to induce ex ante effort, the workers have to believe that the stock grant will be larger when the shock does not occur. But once the shock has not occurred the firm has no incentive to provide the larger grant because no additional effort is required. Hence the firm would have an incentive to renege on the promise, or to misrepresent the state. Note that such a time inconsistency problem does not occur with options compensation because the firm voluntarily reprices the options when the shock occurs because this is in the firm's interest. In summary, while contingent stock compensation can potentially resolve these agency problems, it is less robust than the other methods of dealing with asymmetric information situations.

\subsection{Accounting Issues}

One of the basic features of this model is that the firm does not face any direct cash flow implications at the initial date when compensation is determined, nor does it face any cash flow consequences of option repricing. This is consistent with the strict interpretation of the FASB regulation both before 2005 and afterward, when firms were required to expense at-the-money options. Such expensing is only used for reporting and not for tax accounting. Therefore any costs associated with either grants or option repricings must be indirect and not easily quantified. It is noteworthy that some firms voluntarily expensed their options even before the rules change. What seems clear is that with the new regulations any new incremental 'cost' of repricing is less than before the change in regulations when with the original exercise price they were not expensed. Therefore our model is even more applicable under the current scenario. As a result our finding that stock can survive as an optimal compensation form remains as relevant as ever.

\section{Conclusions}

This paper has highlighted some important differences between straight stock compensation and option compensation in an agency model with multiple periods and information revelation over time. As compared with extant views, we do not find universal domination of options over stock. Stock has certain commitment properties that options do not have. We have related the respective uses to the nature of industrial competition both from the product market as well as the labor market perspective. 
It is often mentioned that the major benefit of options is that they have the same incentive properties as stock, at lower cost, i.e., the firm can 'afford' to give up a greater share of potential dilution because it is receiving the exercise price as compensation. This potential benefit, however, has a serious limitation when product market competition is considered. The provision of options to existing employees means that they will also share in the appreciation of value if rival firms workers are bid away. This lessens the 'toughness' with which a given firm can compete in the product markets. As a result ex ante shareholder value may be lower than when stock is utilized. When such conditions do not exist, however, the flexibility of options is still better than the commitment afforded by the use of stock. The basic driving force for this result occurs when options are set at the money. It is clear that this result is preserved as long as options are set near the money.

This paper points out the importance that product market competition has when the supply of productive staff is limited. This is especially true for high technology industries. We have argued that when the need for frequent revisions is great and that when these revisions tend to occur contemporaneously across firms in the same industry, then firms respond by using options. However as this frequency becomes less because the industry is more stable, or if good news to one firm makes it more likely that bad news has occurred for its rival, then firms might optimally respond by changing their method of compensation to stock. This conclusion is reinforced in situations where there are large gains to leadership in an industry. Therefore we find an important difference between a situation where an industry is already dominated by a firm (in which case options are utilized) and when the potential for domination is great (in which case stock should be utilized). These considerations can potentially explain some of the changes that have occurred in high technology industries as they have matured and developed increased customer demands over the last decade. .

It is clear from these investigations that the extent to which firms can profit in competition with their rivals is determined by and therefore impacts their choice of incentive-based compensation. The optimal responses in this more interesting setting are not as obvious as when a firm views itself in isolation from others. As firms begin to recognize their potential opportunities as well as vulnerabilities, one would predict that industry structure will take its rightful place as a key driver of compensation policy. 


\section{A Appendix}

\section{A.1 Proof of Proposition 1}

Let $s_{0}^{*}$ be the solution to (3), the initial amount of stock granted to the workers. Define the following:

$$
\bar{s}_{1}=\frac{\mu_{1}}{\pi_{m}\left(c_{1}\right)-\pi_{m}\left(c_{2}\right)} \text { and } \quad \bar{s}_{2}=\frac{\mu_{2}}{\pi_{m}\left(c_{2}\right)}
$$

where $\bar{s}_{1}$ and $\bar{s}_{2}$ are the amounts of stock granted in the second period if the incentive compatibility constraints (5) and (6) are binding, respectively. From condition (2), we know

$$
\frac{\mu_{2}}{\mu_{1}}>\frac{\pi_{m}\left(c_{2}\right)}{\pi_{m}\left(c_{1}\right)-\pi_{m}\left(c_{2}\right)}
$$

and thus $\bar{s}_{1}<\bar{s}_{2}$.

There are three mutually exclusive cases: (i) $s_{0}^{*} \leq \bar{s}_{1}<\bar{s}_{2}$, (ii) $\bar{s}_{1}<s_{0}^{*} \leq \bar{s}_{2}$, and (iii) $\bar{s}_{1}<\bar{s}_{2}<s_{0}^{*}$, one of which would characterize the solution to the principal-agent problem (3). Consider case (i) first. Since $s_{0}^{*} \leq \bar{s}_{1}<\bar{s}_{2}$, the second-period incentive compatibility constraints (5) and (6) are both binding. Substituting $s_{1}=\bar{s}_{1}$ and $s_{2}=\bar{s}_{2}$ into the first-period incentive compatibility constraint (4) yields

$$
\frac{p \mu_{1} \pi_{m}\left(c_{2}\right)}{\pi_{m}\left(c_{1}\right)-\pi_{m}\left(c_{2}\right)} \geq v
$$

which violates assumption (1). Hence, $s_{0}^{*}>\bar{s}_{1}$, implying that the second-period incentive compatibility constraint in the no-shock state is never binding.

Now consider case (ii). Since $\bar{s}_{1}<s_{0}^{*} \leq \bar{s}_{2}$, the first-period incentive compatibility constraint (4) and the second-period incentive compatibility constraint (6) are both binding. Substituting $s_{1}=s_{0}^{*}$ and $s_{2}=\bar{s}_{2}$ into the binding constraint (4) yields

$$
s_{0}^{*}=\frac{(v / p)+\mu_{1}}{\pi_{m}\left(c_{1}\right)}
$$

which does not exceed $\bar{s}_{2}$ if

$$
\frac{v}{p} \leq \frac{\mu_{2} \pi_{m}\left(c_{1}\right)}{\pi_{m}\left(c_{2}\right)}-\mu_{1}
$$


This is condition (10) in the proposition. Hence, if the above condition holds, the solution to the principal-agent problem is given by $s_{0}=s_{1}=s_{0}^{*}$ and $s_{2}=\bar{s}_{2}$.

Finally, consider case (iii). Since $\bar{s}_{1}<\bar{s}_{2}<s_{0}^{*}$, the first-period incentive compatibility constraint (4) is binding but the second-period incentive compatibility constraints (5) and (6) are not. Substituting $s_{1}=s_{2}=s_{0}^{*}$ into the binding constraint (4) yields

$$
s_{0}^{*}=\frac{(v / p)-\left(\mu_{2}-\mu_{1}\right)}{\pi_{m}\left(c_{1}\right)-\pi_{m}\left(c_{2}\right)}
$$

which exceeds $\bar{s}_{2}$ if

$$
\frac{v}{p}>\frac{\mu_{2} \pi_{m}\left(c_{1}\right)}{\pi_{m}\left(c_{2}\right)}-\mu_{1}
$$

This is condition (9) in the appendix. Hence, if the above condition holds, the solution to the principalagent problem is given by $s_{0}=s_{1}=s_{2}=s_{0}^{*}$.

\section{References}

Acharya, V., K. John and R. Sundaram (2000), "On the Optimality of Resetting Executive Stock Options," Journal of Financial Economics, 57, 65-101.

Blasi, J., D. Kruse and A. Bernstein (2003), In the Company of Owners: The Truth About Stock Options (And Why Every Employee Should Have Them), Basic Books.

Brander, J. and T. Lewis (1986), "Oligopoly and Financial Structure: The Limited Liability Effect," American Economic Review, 76, 956-970.

Cadenillas, A., J. Cvitanić and F. Zapatero (2004), "Leverage Decision and Manager Compensation with Choice of Effort and Volatility," Journal of Financial Economics, 73, 71-92.

Carter, M. and L. Lynch (2001), "An Examination of Executive Stock Option Repricing," Journal of Financial Economics, 61, 207-225.

Chidambaran, N. and N. Prabhala (2003), "Executive Stock Options Repricing, Internal Governance Mechanisms, and Management Turnover," Journal of Financial Economics, 69, 153-189.

Dittmann, I. and E. G. Maug (2007), "Lower Salaries and No Options? On the Optimal Structure of Executive Pay," Journal of Finance, 303-343.

Feltham, G. and M. Wu (2001), "Incentive Efficiency of Stock Versus Options," Review of Accounting Studies, 6, 7-28.

Grein, B., J. Hand and K. Klassen (2005), "Stock Price Reactions to the Repricing of Employee Stock Options," Contemporary Accounting Research, 22, 791-828. 
Hall, B. (2002), "Incentive Strategy II: Executive Compensation and Ownership Structure," Harvard Business School, 9-902-134.

Hall, B. and K. Murphy (2000), "Optimal Exercise Prices for Executive Stock Options," American Economic Review, 90, 209-214.

Ingersoll, J. (2006), “The Subjective and Objective Evaluation of Incentive Stock Options," Journal of Business, 79, 453-487.

Jin, L. and L. Meulbroek (2002), "Do Underwater Executive Stock Options Still Align Incentives? The Effect of Stock Price Movements on Managerial Incentive-Alignment," Harvard Business School working paper.

Kahl, M., J. Liu and F. Longstaff (2003), "Paper Millionaires: How Valuable is Stock to a Stockholder Whos is Restricted From Selling It?" Journal of Financial Economics, 67, 385-410.

Lie, E. (2005), "On the Timing of CEO Stock Option Awards," Management Science, 51, 802-812.

Maksimovic, V. (1988), "Capital Structure in Repeated Oligopolies," Rand Journal of Economics, 19, 389-407.

Mercer (2006), 2005 WSJ/Mercer CEO Compensation Survey and Trends, The Wall Street Journal/Mercer Human Resource Consulting.

Saly, P. (1994), "Repricing Executive Stock Options in a Down Market," Journal of Accounting and Economics, 18, 325-356.

Yang, J. and W. Carleton (2002), "Recission and Repricing of Executive Stock Options," University of Arizona working paper. 